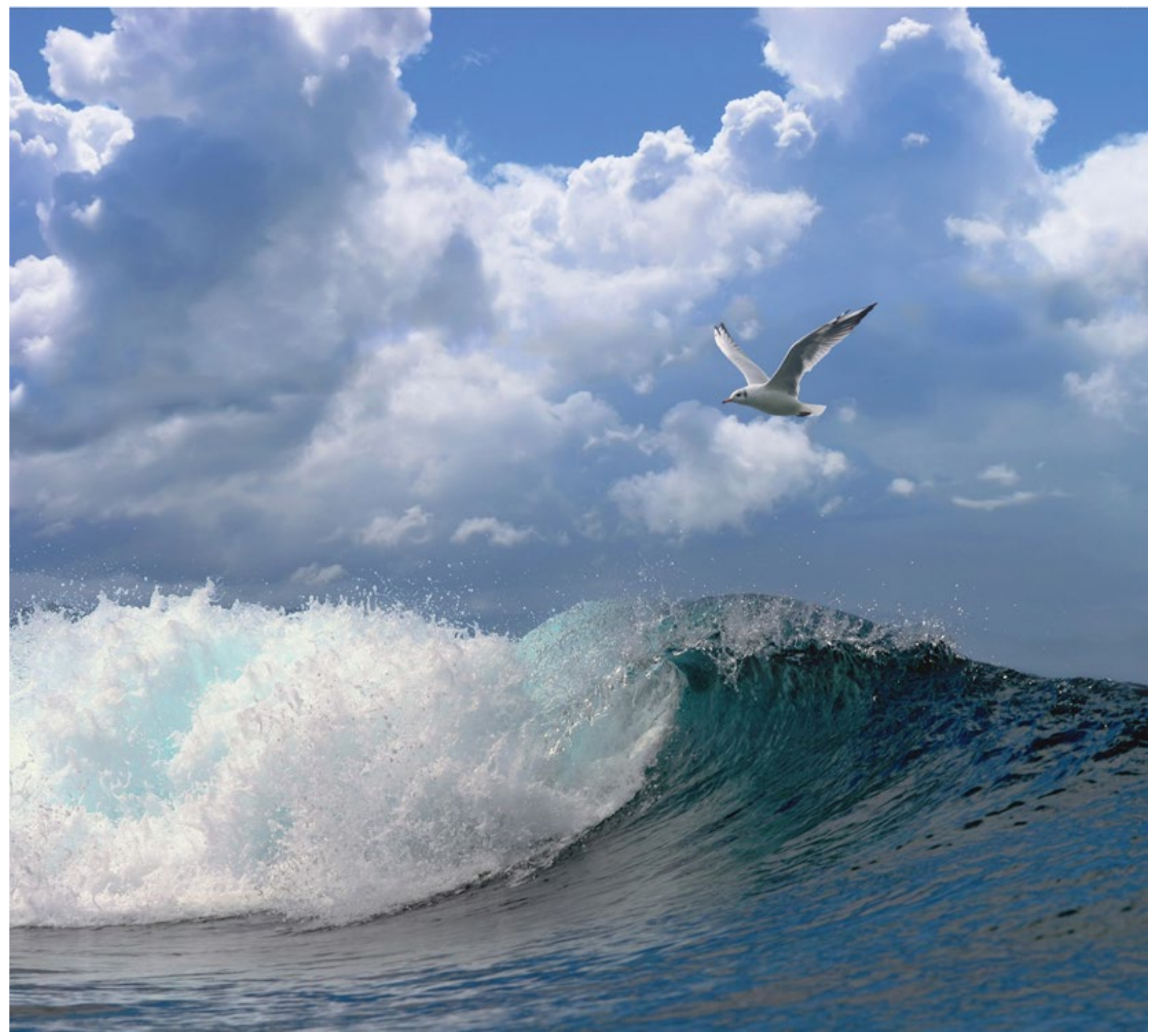

Literatuuronderzoek naar effecten van de configuratie van MZI-systemen op de productie van mosselzaad 


\title{
Literatuuronderzoek naar effecten van de configuratie van MZI-systemen op de productie van mosselzaad
}

\author{
Auteur(s): Jacob J. Capelle
}

Publicatiedatum: 19 februari 2018

Wageningen Marine Research Yerseke

Wageningen Marine Research rapport C011/18 
Capelle, J.J., 2018. Literatuuronderzoek naar effecten van de configuratie van MZI-systemen op de productie van mosselzaad Wageningen Marine Research Wageningen UR (University \& Research centre), Wageningen Marine Research rapport C011/18. 155 blz.

Keywords: MZI, productie, depletie, stroming

Opdrachtgever: Haans Advocaten Bergen op Zoom BV

T.a.v.: mr. M.J. van Langevelde

Postbus 101

4600 AC Bergen op Zoom

Dit rapport is gratis te downloaden van https://doi.org/10.18174/529714

Wageningen Marine Research verstrekt geen gedrukte exemplaren van rapporten.

Wageningen Marine Research is ISO 9001:2015 gecertificeerd.

(C) Wageningen Marine Research

Wageningen Marine Research, instituut binnen Wageningen Marine Research aanvaardt geen aansprakelijkheid voor gevolgschade, de rechtspersoon Stichting Wageningen noch voor schade welke voortvloeit uit toepassingen van de resultaten van Research, hierbij vertegenwoordigd door Ir. werkzaamheden of andere gegevens verkregen van Wageningen Marine Research. Drs. M.T. van Manen, directeur bedrijfsvoering Opdrachtgever vrijwaart Wageningen Marine Research van aanspraken van derden in verband met deze toepassing.

KvK nr. 09098104,

WMR BTW nr. NL 8113.83.696.B16.

Code BIC/SWIFT address: RABONL2U

IBAN code: NL 73 RABO 0373599285
Alle rechten voorbehouden. Niets uit deze uitgave mag weergegeven en/of gepubliceerd worden, gefotokopieerd of op enige andere manier gebruikt worden zonder schriftelijke toestemming van de uitgever of auteur.

A_4_3_1 V30 (2020)

Wageningen Marine Research rapport C011/18 | 2 van 15 


\section{Inhoud}

$\begin{array}{lr}\text { Samenvatting } & 4\end{array}$

$1 \quad$ Inleiding $r$

2 Effecten van off-bottom mosselkweeksystemen op de stroming 7

$\begin{array}{llr}3 & \text { Broedval en stroming } & 8\end{array}$

$4 \quad$ Voedseldepletie in off-bottom mosselkweek systemen $\quad 9$

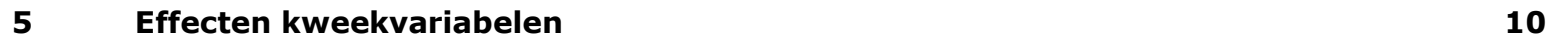

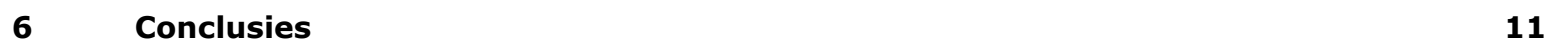

$\begin{array}{lr}\text { Literatuur } & 12\end{array}$

$\begin{array}{lr}\text { Verantwoording } & 14\end{array}$ 


\section{Samenvatting}

Mosselzaad Invang Installaties (MZIs) zijn drijvende systemen met substraat om mossellarven in te vangen als grondstof voor de bodemkweek. Met betrekking tot de inrichting van het MZI-systeem speelt de omgeving een belangrijke rol. De sleutelfactoren die hier van invloed op zijn, zijn:

stroomsnelheid, stroomrichting en voedselconcentratie. Op deze factoren heeft een kweker geen invloed. De variabelen waar een kweker wel invloed op heeft is de configuratie van de systemen op locatie, vooral in het aantal systemen, de hoeveelheid substraat en de dichtheid van de systemen (\#systemen per ha). Het proces waarbij de configuratie van MZI-systemen een negatief effect heeft op de productie van deze systemen ook wel aangeduid met 'schaduwwerking'.

Voorliggend literatuuronderzoek geeft een overzicht in hoeverre de configuratie van de MZI-systemen in relatie tot de omgevingsfactoren de productie van MZI-mosselzaad kan beïnvloeden.

Ruimtelijke variatie in mosselproductie binnen off-bottom systemen is aangetoond voor hangcultuursystemen (longlines, vlotten met substraat) en bij MZIs. Oorzaak hiervan is de weerstand die deze systemen hebben op het instromende water, die weerstand veroorzaakt een afname in stroomsnelheid. De afname in stroomsnelheid kan in combinatie met de filtratie van mosselen leidden tot lokale voedseldepletie binnen in het kweeksysteem. Door depletie wordt de groei geremd en neemt de ruimtelijke variatie in productie binnen het systeem toe. De meeste studies hierover zijn gericht op hangcultuursystemen (longlines en vlotten met substraat) in laag dynamische gebieden en er zijn weinig studies uitgevoerd naar MZI-systemen in hoog dynamische gebieden met hoge stroomsnelheden.

Uit de literatuur kan geconcludeerd worden dat configuratie van de kweeksystemen gebruikt kan worden als sturende variabele in het off-bottom kweekproces om voedseldepletie te voorkomen. Hierbij werd tussenruimte (ruimtes tussen het substraat en tussen de systemen) naar voren gebracht als de sleutelvariabele waarmee ruimtelijke variatie in groei en productie het beste kan worden verklaard. Er is één studie waarin specifiek aan ruimtelijke variatie in mosselkwaliteit binnen MZIsystemen in hoog dynamische gebieden (Waddenzee, Oosterschelde, Voordelta) gemeten is. Voor de meeste MZI-locaties in deze studie werd geen ruimtelijk effect in productie gemeten binnen de ruimtelijke kweekunits (met andere woorden: productie was vergelijkbaar aan de randen en in het midden van het systeem). Op één locatie in de Waddenzee werd wel verminderde productie gemeten. 
Ontwikkelingen in de mosselsector hebben geleid tot een toenemend gebruik van Mosselzaad Invang Installaties (MZIs) om te voorzien in mosselzaad als grondstof voor de bodemkweek (zie onder andere Scholten 2007, Kamermans et al. 2014, Capelle \& van Stralen 2017). MZI's bestaan uit drijvers (boeien, buizen) of frames met daaraan substraat in de vorm van touwen of netten. Op dit substraat kunnen in het voorjaar en de vroege zomer de van nature in het water aanwezige mossellarven zich hechten. Het aldus gehechte mosselzaad kan vervolgens in de waterkolom uitgroeien tot het een geschikte grootte heeft om geoogst te worden om vervolgens uitgezaaid te worden op de kweekpercelen. Productie van mosselzaad op een MZI-systeem kan uitgedrukt worden in kg mosselzaad per meter touw of per vierkante meter net (Capelle \& van Stralen 2017). Deze productie is van een aantal factoren afhankelijk.

Broedval: er zullen voldoende larven aanwezig moeten zijn om zich te vestigen op het substraat en het substraat moet geschikt zijn voor vestiging (bijvoorbeeld niet gehinderd door aangroei).

Groei: na broedval gaan de mosselzaadjes die zich op het substraat gehecht hebben groeien. Mosselen zijn voor voedsel volledig aangewezen op de omgeving. Dit voedsel - voornamelijk in de vorm van fytoplankton - wordt aangevoerd door het water, waarbij dus voldoende verversing nodig is. Voor een goede groei is dus stromend voedselrijk water nodig.

Overleving: er zijn verschillende factoren die ervoor zorgen dat een deel van het mosselzaad op de MZIs het niet overleeft. Concurrentie om voedsel of plaats met andere mosselen (interspecifiek) of met andere dier- of plantensoorten (intraspecifiek) kan sterfte tot gevolg hebben. Daarnaast vindt er sterfte plaats door predatie, waarbij mosselen geconsumeerd worden door bijvoorbeeld zeesterren, vissen, krabben of vogels. Ten slotte kan het mosselzaad ook door diverse oorzaken (bijvoorbeeld door sterke stroming, hoge mosseldichtheid, of stormen van het substraat af vallen (afvalverlies), waardoor het voor de oogst verloren is.

Haalbare productie van een MZI-locatie is ook afhankelijk van de productiedraagkracht van de locatie. De hoeveelheid beschikbaar voedsel voor de mosselen bepaalt de productiviteit van een MZI-locatie. Het inschatten van deze productiedraagkracht is complex, en vereist een vergaand begrip van de interacties tussen het MZI-systeem en de omgeving (McKindsey et al. 2006). Dit maakt ook het inrichten van een MZI-locatie complex, omdat de algehele productie gemaximaliseerd dient te worden terwijl variatie binnen de locatie geminimaliseerd dient te worden. Er moet dus met betrekking tot de inrichting van het systeem rekening gehouden worden met de omgeving. De sleutelfactoren die hier van invloed op zijn, zijn: stroomsnelheid, stroomrichting en voedselconcentratie (Rosland et al. 2011). Op deze factoren heeft een kweker geen invloed. De variabelen waar een kweker wel invloed op heeft is de configuratie van de systemen op locatie, vooral in het aantal systemen, de hoeveelheid substraat en de dichtheid van de systemen (\#systemen per ha).

Het proces waarbij de configuratie van MZI-systemen een negatief effect heeft op de productie van deze systemen ook wel aangeduid met 'schaduwwerking'.

Voorliggend literatuuronderzoek geeft een overzicht in hoeverre de configuratie van de MZI-systemen in relatie tot de omgevingsfactoren de productie van MZI-mosselzaad kan beïnvloeden.

\section{MZI-systemen}

In hoofdstuk 2 wordt een overzicht gegeven over in hoeverre kweeksystemen de stroming beïnvloeden. In hoofdstuk 3 wordt ingegaan op het mogelijke effect van deze veranderingen op de broedval van mosselen. Hoofdstuk 4 beschrijft mogelijke effecten van omgevingsfactoren op de voedselvoorziening voor mosselen, en daarmee op de productie van het systeem en in hoofdstuk 5 wordt beschreven welke factoren in de configuratie van kweeksystemen de meeste invloed hebben op de productie van off-bottom kweeksystemen. 
De (internationale) literatuur over dit onderwerp gaat in op off-bottom kweeksystemen, vooral longlines en vlotsystemen voor productie van consumptie mosselen. Specifieke studies naar MZIsystemen over dit onderwerp zijn nauwelijks verricht. Daarom zal het grootste gedeelte van deze literatuurstudie ingaan op effecten gemeten bij longline en vlotsystemen. Longlines en vlotsystemen zijn ook als MZI gebruikt, in dit rapport refereren de termen longlines en vlot(systemen) echter uitsluitend naar hangcultuursystemen, waarin off-bottom consumptiemosselen gekweekt worden. Alle systemen die uitsluitend voor de invang van zaad als uitgangsmateriaal voor de mossel bodemcultuur gebruikt worden, worden aangeduid als MZI(-systemen). Er zijn een aantal verschillen tussen deze systemen en MZI-systemen: MZI-systemen worden exclusief gebruikt voor de invang van mosselzaad, dit limiteert het gebruik tot een korte periode waarbij de meeste productie in de zomer plaatsvindt. In de zomer is het vaak rustig weer en is veel voedsel voorhanden zodat het zaad op de systemen hard groeit. Longlines en vlotsystemen zijn in de regel gesitueerd in laag-dynamische gebieden, om het afvalverlies voor (grote) mosselen te minimaliseren. MZIs zijn met name geplaatst in hoogdynamische gebieden in de Waddenzee en Oosterschelde, en het mosselzaad wordt geoogst voor het moment dat het afvalverliesrisico hoog wordt. 


\section{Effecten van off-bottom mosselkweeksystemen op de stroming}

MZI-drijvers zijn verankerd aan palen of met ankers op vaste posities en het substraat hangt in de bovenste 3-5 meter van de waterkolom. Het water stroomt door de systemen heen en ervaart daarbij weerstand waardoor het stromingsprofiel veranderd en de stroomsnelheid afgeremd wordt. Waterbeweging in en rondom MZIs zijn nog niet gekwantificeerd. Er zijn in diverse delen van de wereld wel metingen verricht aan vergelijkbare structuren, namelijk aan drijvende longlines en aan vlotten met substraat. Metingen laten zien dat de waterstroming binnen longlines en vlotsystemen door deze systemen gereduceerd wordt (Boyd \& Heasman 1998, Heasman et al. 1998, Grant \& Bacher 2001, Strohmeier et al. 2005, Riethmüller et al. 2006, Aure et al. 2007, Stevens et al. 2008, O'Donncha et al. 2013, Aguiar et al. 2017).

In een longline systeem in Noorwegen was de stroomsnelheid 30 meter vanaf de rand van het systeem met meer dan 70\% afgenomen (Strohmeier et al. 2005, Strohmeier et al. 2008). Ook in longlines in Ierland werd een afname in stroomsnelheid gevonden van rond de 30\% (O'Donncha et al. 2013). In Spanje remden de vlotten met substraat de stroomsnelheid met $25-62 \%$ af (Cranford et al. 2014). In Saldanha Bay (Zuid Afrika) werd de stroomsnelheid met een factor 6 verlaagd in het midden van het vlot Boyd and Heasman (1998). Op grotere schaal zoals gebieden waar grote concentraties kweeksystemen liggen kan de doorstroming in heel het kweekgebied aanmerkelijk lager zijn, zoals berekend voor Sungo Bay in China (Grant \& Bacher 2001).

Verandering in stroomsnelheid ontstaan vooral door de weerstand die het substraat met mosselen (en aangroei) aan het langsstromende water geeft (Stevens et al. 2007). Er zijn verschillende wiskundige modellen ontwikkeld om veranderingen in stroming rond en in longlines en vlotten met substraat in kaart te brengen (Aure et al. 2007, Rosland et al. 2011, O'Donncha et al. 2013, Newell \& Richardson 2014, Wang et al. 2015). Door de complexiteit en een gebrek aan empirische gegevens, hebben deze modellen echter een relatief grote onbetrouwbaarheidsmarge (Cranford et al. 2014). Als bijvoorbeeld in een longline systeem het water langs de lijnen met mosselen stroomt ontstaat er turbulentie waardoor in combinatie met de lagere stroomsnelheid de weerstand van de volgende lijn stroomafwaarts afneemt, of er kan sprake zijn van een aanzuigende werking van onderaf (Stevens et al. 2007, Cranford et al. 2014).

De stroomsnelheden die in voorgaande studies gerapporteerd zijn (maximale waardes $0.3 \mathrm{~m} \mathrm{~s}^{-1}$ ) zijn een aantal maal lager dan wat bij MZI-systemen in de Waddenzee gevonden wordt. Voor de Marsdiep inlaat worden maximale stroomsnelheden van 1.0-1.5 $\mathrm{m} \mathrm{s}^{-1}$ gerapporteerd (Ridderinkhof et al. 2002). Het is onbekend in welke mate MZI systemen in hoog dynamische gebieden de stromingspatronen beïnvloeden. Op basis van (Petersen et al. 2008 en Cranford et al. 2014) kan mogelijk verwacht worden dat de effecten van de systemen op de stroming relatief zelfs hoger is in hoog dynamische gebieden.

Behalve binnen de kweeksystemen zijn er ook effecten op de waterstroming rondom de systemen. In mosselcultures in Spanje werd stroomafwaarts van de vlotsystemen, door vortices (draaiende beweging in een vloeistof), een voedselarme zone van 30-50 m gevonden (Riethmüller et al. 2006). Daarna herstelde de stroming en hiermee toevoer van het voedsel zich weer. Om die reden wordt een afstand van 100 tussen de vlotten geadviseerd in deze Spaanse situatie waarbij de structuren elkaar dan niet in de weg zitten (Petersen et al. 2008). 


\section{$3 \quad$ Variatie in broedvalsucces}

De variatie in stroomsnelheden veroorzaakt door de systemen kunnen theoretisch een effect hebben op de vestigingskans van mossellarven. Hier is echter weinig over bekend. $\mathrm{Er}$ is wel een studie uitgevoerd onder gecontroleerde omstandigheden, waarin mossellarven blootgesteld werden aan verschillende stroomsnelheden (Pernet et al. 2003). De resultaten hiervan laten zien dat mosselen zich actief vestigen in micro-habitatten waar de schuifspanning en stroming relatief laag is. Als de stroming langzaam opgevoerd werd, waren de mossellarven niet meer in staat actief een geschikte plaats te selecteren. Ze gedroegen zich dan als passieve deeltjes en het broedvalsucces nam af.

Als er structureel voedseltekort optreedt binnen de MZI kan dit gevolgen hebben voor de prestaties van de mosselen. Constante blootstelling van mossellarven aan een laag voedselaanbod leidde bij juveniele mosselen in een experimentele setting (Mytilus galloprovincialis) tot grotere verliezen en tragere groei (Phillips 2014). 


\section{$4 \quad$ Voedseldepletie in off-bottom mosselkweek systemen}

Groei van mosselen wordt bepaald door temperatuur en voedselbeschikbaarheid (Smaal \& Van Stralen 1990, Troost et al. 2010). Voedselbeschikbaarheid is op zijn beurt weer afhankelijk van de omgeving, vooral van de voedselconcentratie, voedselsamenstelling en stroming (Fréchette et al. 1989, Smaal \& Van Stralen 1990, Bayne 1998, Cranford \& Hill 1999). Wanneer mosselen in hoge dichtheden voorkomen kan concurrentie om voedsel optreden, en de groei kan hierdoor achterblijven (AlunnoBruscia et al. 2000). Voedseldepletie treedt op als het voedsel (fytoplankton) sneller opgenomen wordt dan dat het door waterstroming of primaire productie aangevuld wordt. Voedseldepletie - wat nauw samenhangt met reductie in stroomsnelheid door kweekstructuren - is een belangrijke indicator voor het vaststellen van de productiedraagkracht van een kweeklocatie (Grant \& Bacher 2001, Grant \& Filgueira 2011).

Kweekstructuren (zoals longlines) worden veelal met de stroomrichting mee geplaatst zodat het water door de ruimtes tussen de structuren door kan stromen, en de weerstand op de systemen minimaal is. De stroomsnelheid van het water neemt af wanneer het door de kweekstructuur stroomt (zie hoofdstuk 2), en in combinatie met de filtratie van de mosselen neemt daarmee ook de concentratie aan voedseldeeltjes stroomafwaarts het systeem af (Aure et al. 2007). Als de kweekstructuren loodrecht op de stroming geplaatst zijn neemt de weerstand van de structuren toe en neemt de stroomsnelheid sneller af, waardoor de kans op depletie verder toeneemt (Petersen et al. 2008).

Er zijn geen wetenschappelijke publicaties beschikbaar die mogelijke voedseldepletie in MZI-systemen beschrijven. Voor andere mosselkweeksystemen (longline, vlotten) zijn wel gegevens beschikbaar. Studies hierover berichtten over afnames van fytoplankton tussen 10 en $80 \%$ binnenin de mosselkweekstructuur (Navarro et al. 1991, Boyd \& Heasman 1998, Heasman et al. 1998, Ogilvie et al. 2000, Strohmeier et al. 2005, Riethmüller et al. 2006, Gibbs 2007, Petersen et al. 2008, Cranford et al. 2014). Het verschil in afname van voedseldeeltjes tussen de verschillende studies hangt vooral af van het voedseltransport (stroming), de grootte (volume) van de structuur, het aantal mosselen en de oriëntatie van de structuren (Duarte et al. 2008, Rosland et al. 2011, Cranford et al. 2014).

Verdeling van voedsel binnen het systeem wordt gecontroleerd door de hydrodynamiek (stromingspatronen) binnen en buiten de kweekstructuur (Cranford et al. 2008). Deze omgevingseffecten kunnen niet gegeneraliseerd worden; of vanuit het ene systeem op het andere systeem geplakt worden. In een productieve omgeving met hoge stroomsnelheden en wind-gedreven menging kan het praktisch erg lastig zijn depletie aan te tonen (Ogilvie et al. 2000, Petersen et al. 2008). In veel gevallen leidt voedseldepletie in het midden, of stroomafwaarts het systeem tot een lagere groei en conditie van de mosselen in het midden van de kweekstructuur (Navarro et al. 1991, Boyd \& Heasman 1998, Karayücel \& Karayücel 2000, Strohmeier et al. 2008).

Er is één studie uitgevoerd naar voedseldepletie binnen MZI-systemen in de Waddenzee en Oosterschelde, waarbij ruimtelijke variatie in vleesgewicht binnen het systeem als indicator voor voedseldepletie is gebruikt (Kamermans et al. 2014a). In deze studie (2013) zijn mosselen verzameld tijdens de oogst, aan de rand en in het midden van de MZIs. Dit onderzoek is uitgevoerd op twee MZIlocaties in de Waddenzee (Gat van Stompe en Zuidmeep), twee locaties in de Oosterschelde (Neeltje Jans en Galgeplaat) en een locatie in de Voordelta (Brouwershavense Gat). Van deze mosselen is de conditie bepaald. Er werd in deze studie op één van de vijf onderzochte locaties, te weten het Gat van Stompe een beter conditie van mosselen gevonden aan de rand van het systeem dan in het midden. Bij de andere locaties kon geen aantoonbaar verschil gevonden worden. 
Ruimte tussen de systemen (systeemdichtheid) wordt aangehaald als belangrijke sturende factor voor het mogelijke optreden van productievermindering. Systeemdichtheid bepaalt namelijk zowel de reductie in stroomsnelheden als de filtratiedruk en dus voedselopname capaciteit van het systeem.

In het duiden van de resultaten voeren de auteurs in Kamermans et al. (2014a) de dichtheid van de systemen (ruimte tussen de netten) op als meest aannemelijke verklaring voor variatie in conditie binnen de systemen van het Gat van Stompe. Gat van Stompe werd in 2013 namelijk minder intensief gebruikt dan de Zuidmeep. Op de Zuidmeep zijn ook metingen verricht en daar is geen ruimtelijk patroon gevonden. Ten opzichte van de Zuidmeep waren de systemen in het Gat van Stompe volgens de auteurs dichter op elkaar geplaatst. Gegevens over mosseldichtheid of afstand tussen de systemen zijn in deze studie niet verzameld, waardoor deze aanname niet kan worden geverifieerd.

In een modelstudie toegespitst op longlines in Noorwegen bleek ruimte tussen de touwen de sleutelvariabele om totale biomassa productie te kunnen simuleren (Rosland et al. 2011). Het model suggereerde een drempelwaarde in de ruimte tussen de touwen. Beneden deze waarde daalden de stroming en filtratie van de mosselen sterk, met als gevolg een afname in groei en een toename van de ruimtelijke variatie in groei. Deze drempelwaarde is sterk afhankelijk van de omgeving en zal voor de voedselrijke en snel stromende Waddenzee anders zijn dan voor de voedselarme en langzaam stromende locatie in Noorwegen.

In een andere studie wordt gerapporteerd dat voor een longline-systeem in Noorwegen (gemiddelde stroomsnelheid 2.5-5.5 $\mathrm{cm} \mathrm{s}^{-1}$ ) de structuren aangepast zijn door meer ruimte tussen de longlines ( $5.5 \mathrm{~m}$ ten opzichte van $1.5 \mathrm{~m}$ ) te creëren. De kleine afstand tussen de longlines zorgde voor te veel weerstand (afname in stroomsnelheid van 70\%) waardoor de voedseltoevoer en daarmee de groei in die mate achterbleef dat rendabel kweken niet mogelijk was (Strohmeier et al. 2005, Strohmeier et al. 2008). In de systemen met meer ruimte tussen de longlines vond in het midden van de systemen nog steeds een fytoplankton reductie van 20-91\% plaats (Strohmeier et al. 2008). In een statistische verkenning naar factoren in de productie van mosselen in de longline in Tracadie Bay in Canada werd de ruimte tussen de touwen als enige verklarende variabele gevonden om gemeten verschillen in mosselgewicht te kunnen verklaren (Drapeau et al. 2006). De modellen in deze studie voorspelden $18 \%$ toename in mosselgewicht ( $34 \mathrm{~mm}$ ) bij een toename van $11 \mathrm{~cm}$ ruimte tussen de touwen. 


\section{Conclusies}

Ruimtelijke variatie in mosselproductie binnen off-bottom systemen is aangetoond voor longlines, vlotten met substraat en bij MZIs. Oorzaak hiervan is de weerstand die deze systemen hebben op het instromende water, die weerstand veroorzaakt een afname in stroomsnelheid. De afname in stroomsnelheid kan in combinatie met de filtratie van mosselen leidden tot lokale voedseldepletie binnen in het kweeksysteem. Door depletie wordt de groei geremd en neemt de ruimtelijke variatie in productie toe. Op basis van deze literatuurstudie is het niet mogelijk conclusies te trekken over de effecten van een afname van stroomsnelheid op broedvalsucces of overleving.

De mate en vorm waarin off-bottom kweekstructuren de stroomsnelheid beïnvloeden, is complex, afhankelijk van de omgeving en gaat gepaard met grote onzekerheid. Het is echter evident dat dit proces op kan treden; in alle hier geciteerde studies over dit onderwerp is dit effect gevonden, of wordt dit effect genoemd. Hierbij moet aangemerkt worden dat de meeste studies gericht zijn op longline en vlot systemen voor de productie van consumptie mosselen in laag dynamische gebieden en dat er weinig studies bekend zijn specifiek voor MZI-systemen in hoog dynamische gebieden met hoge stroomsnelheden. In de meeste gevallen wordt voedseldepletie en/of verminderde productie gevonden in het midden van het kweeksysteem.

Uit de literatuur kan geconcludeerd worden dat configuratie van de kweeksystemen gebruikt kan worden als sturende variabele in het off-bottom kweekproces om voedseldepletie te voorkomen. Hierbij werd tussenruimte (ruimtes tussen het substraat en tussen de systemen) naar voren gebracht als de sleutelvariabele waarmee ruimtelijke variatie in groei en productie het beste kan worden verklaard. Dit is aangetoond in zowel experimentele studies als in statistische en wiskundige modelsimulaties Het vergroten van de ruimte tussen het substraat leidt in een aantal studies/modelscenario's tot een toename van de groei en productie. Deze studies zijn uitgevoerd met longlines in laag dynamische gebieden. $\mathrm{Er}$ is één studie waarin specifiek aan ruimtelijke variatie in mosselkwaliteit binnen MZI-systemen in hoog dynamische gebieden (Waddenzee, Oosterschelde, Voordelta) gemeten is. Voor de meeste MZI locaties in deze studie werd geen ruimtelijk effect in productie gemeten binnen de ruimtelijke kweekunits (met andere woorden: productie was vergelijkbaar aan de randen en in het midden van het systeem). Op één locatie in de Waddenzee werd wel verminderde productie gemeten. 


\section{Literatuur}

Aguiar E, Piedracoba S, Álvarez-Salgado XA, Labarta U (2017) Circulation of water through a mussel raft: clearance area vs. idealized linear flows. Rev Aquacult 9:3-22

Alunno-Bruscia M, Petraitis PS, Bourget E, Fréchette M (2000) Body size-density relationship for Mytilus edulis in an experimental food-regulated situation. Oikos 90:28-42

Aure J, Strohmeier T, Strand $\varnothing$ (2007) Modelling current speed and carrying capacity in long-line blue mussel (Mytilus edulis) farms. Aquaculture research 38:304-312

Bayne BL (1998) The physiology of suspension feeding by bivalve molluscs: An introduction to the Plymouth 'TROPHEE' workshop. Journal of Experimental Marine Biology and Ecology 219:1-19

Boyd A, Heasman K (1998) Shellfish mariculture in the Benguela system: water flow patterns within a mussel farm in Saldanha Bay, South Africa. Journal of Shellfish Research 17:25-32

Capelle JJ, van Stralen MR (2017) Invang mosselzaad in MZIs, resulaten 2016. In. Wageningen Marine Research, Yerseke

Cranford PJ, Duarte P, Robinson SMC, Fernández-Reiriz MJ, Labarta U (2014) Suspended particulate matter depletion and flow modification inside mussel (Mytilus galloprovincialis) culture rafts in the Ría de Betanzos, Spain. Journal of Experimental Marine Biology and Ecology 452:70-81

Cranford PJ, Hill PS (1999) Seasonal variation in food utilization by the suspension-feeding bivalve molluscs Mytilus edulis and Placopecten magellanicus. Marine Ecology Progress Series 190:223-239

Cranford PJ, Li W, Strand $\varnothing$, Strohmeier T Phytoplankton depletion by mussel aquaculture: high resolution mapping, ecosystem modeling and potential indicators of ecological carrying capacity. In. ICES

Drapeau A, Comeau LA, Landry T, Stryhn H, Davidson J (2006) Association between longline design and mussel productivity in Prince Edward Island, Canada. Aquaculture 261:879-889

Duarte P, Labarta U, Fernández-Reiriz MJ (2008) Modelling local food depletion effects in mussel rafts of Galician Rias. Aquaculture 274:300-312

Fréchette M, Butman CA, Geyer WR (1989) The importance of boundary-layer flows in supplying phytoplankton to the benthic suspension feeder, Mytilus edulis L. Limnology \& Oceanography 34:19-36

Gibbs MT (2007) Sustainability performance indicators for suspended bivalve aquaculture activities. Ecological Indicators 7:94-107

Grant J, Bacher C (2001) A numerical model of flow modification induced by suspended aquaculture in a Chinese bay. Canadian Journal of Fisheries and Aquatic Sciences 58:1003-1011

Grant J, Filgueira R (2011) The Application of Dynamic Modeling to Prediction of Production Carrying Capacity in Shellfish Farming. In: Shellfish Aquaculture and the Environment. Wiley-Blackwell

Heasman KG, Pitcher GC, McQquaid CD, Hecht T (1998) Shellfish mariculture in the Benguela system: Raft culture of Mytilus Galloprovincialis and the effect of rope spacing on food extraction, growth rate, production, and condition of mussels. Journal of Shellfish Research 17:33-39

Kamermans P, Brummelhuis E, van Gool A (2014a) MZI-mosselgewicht als indicator van voedselomstandigheden. In. IMARES

Kamermans P, Smit CJ, Wijsman JWM, Smaal AC (2014b) Meerjarige effect- en productiemetingen aan MZI's in de Westelijke Waddenzee, Oosterschelde en Voordelta: samenvattend eindrapport [Long term measurements on effects and production of SMCs in the western Wadden Sea]. In. IMARES Wageningen UR, Yerseke

Karayücel S, Karayücel I (2000) Influence of stock and site on growth, mortality and shell morphology in cultivated blue mussels (Mytilus edulis L.) in two Scottish sea lochs. Israeli Journal of Aquaculture-Bamidgeh 52:98-110

McKindsey CW, Thetmeyer H, Landry T, Silvert W (2006) Review of recent carrying capacity models for bivalve culture and recommendations for research and management. Aquaculture 261:451-462

Navarro E, Iglesias J, Camacho AP, Labarta U, Beiras R (1991) The physiological energetics of mussels (Mytilus galloprovincialis Lmk) from different cultivation rafts in the Ria de Arosa (Galicia, NW Spain). Aquaculture 94:197-212

Newell CR, Richardson J (2014) The effects of ambient and aquaculture structure hydrodynamics on the food supply and demand of mussel rafts. Journal of Shellfish Research 33:257-272

O'Donncha F, Hartnett M, Nash S (2013) Physical and numerical investigation of the hydrodynamic implications of aquaculture farms. Aquacultural engineering 52:14-26

Ogilvie SC, Ross AH, Schiel DR (2000) Phytoplankton biomass associated with mussel farms in Beatrix Bay, New Zealand. Aquaculture 181:71-80 
Pernet F, Tremblay R, Bourget E (2003) Settlement success, spatial pattern and behavior of mussel larvae Mytilus spp. in experimental 'downwelling'systems of varying velocity and turbulence. Marine Ecology Progress Series 260:125-140

Petersen JK, Nielsen TG, van Duren L, Maar M (2008) Depletion of plankton in a raft culture of Mytilus galloprovincialis in Ría de Vigo, NW Spain. I. Phytoplankton. Aquatic Biology 4:113-125

Phillips NE (2004) Variable timing of larval food has consequences for early juvenile performance in a marine mussel. Ecology 85:2341-2346

Rajagopal S, Venugopalan VP, Nair KVK, Van der Velde G, Jenner HA (1998) Settlement and growth of the green mussel Perna viridis (L.) in coastal waters: influence of water velocity. Aquatic Ecology 32:313-322

Ridderinkhof H, Van Haren H, Eijgenraam F, Hillebrand T (2002) Ferry observations on temperature, salinity and currents in the Marsdiep tidal inlet between the North Sea and Wadden Sea. In: Elsevier Oceanography Series, Book 66. Elsevier

Riethmüller R, Jäger N, Häse C, Fernandes L, Neves R (2006) Flow patterns around and within a raft mussel farm in the Ria de Vigo, Spain. GKKS, Germany

Rosland R, Bacher C, Strand $\varnothing$, Aure J, Strohmeier T (2011) Modelling growth variability in longline mussel farms as a function of stocking density and farm design. Journal of Sea Research 66:318-330

Scholten MCT (2007) Perspectieven voor mosselzaadinvang (MZI) in de Nederlandse kustwateren : een evaluatie van de proefperiode 2006-2007. In. IMARES, Den Helder

Smaal AC, Van Stralen MR (1990) Average annual growth and condition of mussels as a function of food source. Hydrobiologia 195:179-188

Stevens C, Plew D, Hartstein N, Fredriksson D (2008) The physics of open-water shellfish aquaculture. Aquacultural Engineering 38:145-160

Stevens C, Plew D, Smith M, Fredriksson D (2007) Hydrodynamic forcing of long-line mussel farms: observations. Journal of waterway, port, coastal, and ocean engineering 133:192-199

Strohmeier T, Aure J, Duinker A, Castberg T, Svardal A, Strand Ø (2005) Flow reduction, seston depletion, meat content and distribution of diarrhetic shellfish toxins in a long-line blue mussel (Mytilus edulis) farm. Journal of Shellfish Research 24:15-23

Strohmeier T, Duinker A, Strand $\varnothing$, Aure J (2008) Temporal and spatial variation in food availability and meat ratio in a longline mussel farm (Mytilus edulis). Aquaculture 276:83-90

Troost TA, Wijsman JWM, Saraiva S, Freitas V (2010) Modelling shellfish growth with dynamic energy budget models: An application for cockles and mussels in the Oosterschelde (southwest Netherlands). Philosophical Transactions of the Royal Society B: Biological Sciences 365:35673577

Wang X-x, Swift MR, Dewhurst T, Tsukrov I, Celikkol B, Newell C (2015) Dynamics of submersible mussel rafts in waves and current. China Ocean Engineering 29:431-444 


\title{
Verantwoording
}

\author{
Rapport: $\quad$ C011/18 \\ Projectnummer: $\quad 4311000006$
}

Dit rapport is met grote zorgvuldigheid tot stand gekomen. De wetenschappelijke kwaliteit is intern getoetst door een collega-onderzoeker en het verantwoordelijk lid van het managementteam van Wageningen Marine Research

Akkoord:

Dr. Ir. H.M. Jansen

Handtekening:

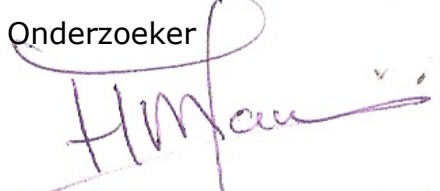

Datum:

19 februari 2018

Akkoord:

Drs. J. Asjes

Manager Integratie

Handtekening:

Datum:

19 februari 2018 
Wageningen Marine Research

T: +31 (0)317480900

E: marine-research@wur.nl

www.wur.nl/marine-research

Bezoekers adres:

- Ankerpark 271781 AG Den Helder

- Korringaweg 7, 4401 NT Yerseke

- Haringkade 1, 1976 CP IJmuiden
Wageningen Marine Research levert met kennis, onafhankelijk wetenschappelijk onderzoek en advies een wezenlijke bijdrage aan een duurzamer, zorgvuldiger beheer, gebruik en bescherming van de natuurlijke rijkdommen in zee-, kust- en zoetwatergebieden. 